\title{
Growing Burden of Hypertension in China: Causes, Challenges, and Opportunities
}

\author{
Zumin Shi ${ }^{1, \neq}$; Xiaomin Sun ${ }^{2}$; Alice F Yan ${ }^{3}$; Youfa Wang ${ }^{2,+\#}$
}

Cardiovascular disease (CVD) is the leading cause of death in China, and an estimated 290 million individuals are affected by CVD in China (1). Hypertension is the most important risk factor of CVD (2). Good control and management of hypertension are vital to prevent CVD and related health and social consequences. Over the past several decades, China has put a significant amount of effort into the battle against hypertension. Yet, the burden of hypertension continues to increase. Here, we described the burden of hypertension and its important risk factors in China.

\section{BURDEN AND CHALLENGES}

The burden of hypertension in China has been increasing over the past several decades. According to the 2002 China National Nutrition and Health Survey, the prevalence of hypertension was $18.0 \%$ (3). Data from China's nationally representative survey conducted 10 years later recruited 174,621 adults aged over 18 years from 31 provincial-level administrative divisions (PLADs) in the mainland of China between 2013-2014 and showed major reversals (4). Overall, the prevalence of hypertension was $27.8 \%$ (4), which was lower than that of the US (29.1\%) and England $(30 \%)$ but higher than that of Canada $(19.5 \%)(5)$.

Another serious challenge is that the prevalence of hypertension was substantially increased, but the levels of awareness, treatment, and management remained low. Among those with hypertension in China, only less than half were aware of their condition, $40.7 \%$ were taking antihypertensive medication, and only 15.3\% achieved blood pressure control (6). Among those treated hypertensive patients, only about $37.5 \%$ had their blood pressure controlled at the desired level. Although the prevalence of awareness in China improved in $2012(46.9 \%)$ over that of $2002(24 \%)$, it was much lower than that in the US $(81 \%)$, Canada (83\%), and England (65\%) (5).

It is worth noting that aging is one of the most important risk factors of hypertension. Among those
65 years and older, the prevalence of hypertension was above $55 \%$ (6). With the population aging, the burden of hypertension and related complications will continue to increase in China. Other important factors that have contributed to the increased burden of hypertension include changes in lifestyle factors (such as dietary patterns) and increased obese/overweight prevalence.

\section{IMPORTANT CAUSES AND DETERMINANTS}

\section{Salt Intake in China}

Salt reduction has been given priority as a hypertension prevention strategy in China. For example, salt restriction spoons were provided by the government to the public for free to reduce salt consumption and complement other salt reduction campaigns (7). Data from China's total diet studies showed that the average amount of sodium consumed from cooking salt decreased from 11.8 grams/day $(\mathrm{g} / \mathrm{d})$ in 2000 to $9.2 \mathrm{~g} / \mathrm{d}$ in $2009-2011$ (8), but this was still much higher than the recommended daily maximum intake of salt $(5 \mathrm{~g} / \mathrm{d})$ and sodium level $(2 \mathrm{~g} / \mathrm{d})$. A metaanalysis of 24-hour urinary sodium excretion found a decreasing trend in the north but an increasing trend in the south (9). However, the reduction in salt intake did not translate into a significant reduction in hypertension rates in China. The prevention of hypertension should not be confined to salt reduction as other factors need to be addressed simultaneously.

\section{Role of Obesity}

Obesity (including overweight) is one of the major risk factors of hypertension. Presently, about $46 \%$ of adults in China are overweight or obese (10). In the China Kadoorie Biobank (CKB) study, general adiposity as reflected by BMI was strongly associated with blood pressure, and the association was $50 \%$ stronger than that observed in Western populations 
(11). Due to social and economic development, the prevalence of obesity and overweight was increased substantially in both adults and children in China. For example, national survey data showed that the prevalence of obesity among children aged 6-17 years increased from $2.1 \%$ in 2002 to $6.4 \%$ in 2012 (12). Prevention of obesity and hypertension in children and adolescents should be given priority as these conditions during this period have long-term effects on health outcomes. Furthermore, data from diverse populations showed childhood blood pressure was associated with blood pressure in later life and that interventions in childhood were important (13).

\section{Early Life Famine Exposure}

In addition to the traditional risk factors of hypertension, early life exposure to famine (such as the Chinese famine between 1959 and 1962) has been shown to increase hypertension risk (14-16). Data from the China Health and Retirement Longitudinal Study (CHARLS) suggested that early life exposure to the Chinese famine exacerbated the association between hypertension and CVD (17). The odds ratio (OR) of hypertension for CVD were 1.69, 2.35, 2.48, 3.35 , and 1.40 among adults in late childhood, midchildhood, early childhood, fetal, and non-exposed cohorts, respectively (17). Regional differences for hypertension may partly be due to different effects of famine exposure in early life as there were also a few studies that showed a link between early life famine exposure and obesity in adulthood in China. Lessons can be learned from famine-related studies. They may also indicate the importance of nutrition intervention during natural disasters such as earthquakes and floods.

\section{Disparities}

The substantial disparity of hypertension by socioeconomic status (SES) must be recognized as those with lower education had a much higher prevalence of hypertension than those with higher education $(36.5 \%$ vs. 9.5\%) (6). Hypertension prevention should target the disadvantaged group. In the past, hypertension was found to impact more people in urban areas than rural areas of China (3). However, recent data showed that there was no significant urban/rural difference in the prevalence of hypertension (6). The rise in the prevalence of hypertension in rural areas is a challenge due to the relatively limited access to health services, especially in cases of CVD events such as stroke. In general, the prevalence of awareness and control of hypertension was lower in rural areas than urban areas $(4,6)$.

Regional differences in the prevalence of hypertension have been observed for a long time (18). Several potential factors have been proposed to explain this difference including differences in dietary habits, alcohol consumption, temperature, and physical activity levels.

More research is needed to explore other factors that may have affected hypertension rate in China. For example, one factor that needed to be examined was selenium intake in the north because selenium intake is responsible for Keshan disease (19). The degree to which selenium levels affected hypertension needed to be studied because several regions of China suffered from inadequate selenium intake. Studying the relationship between serum selenium and hypertension yielded inconsistent findings with both positive and inverse associations being reported (20-21), thereby necessitating further studies to establish this relationship.

Gender differences in the prevalence of hypertension has been consistently observed with a higher rate in men than women $(4,6)$. The gap may be partly due to unhealthy lifestyles (e.g. smoking and alcohol drinking) in men (22).

\section{Role of Modern Diet and Lifestyle}

In recent decades, there have been substantial changes in people's dietary intakes in China. The consumption of energy-dense diets has increased substantially, and such diets are linked to an increased cardiometabolic risk factors (23). Based on the 2002 Chinese National Nutrition Survey, exposure to the modern diet in adulthood modified the association between famine exposure and metabolic syndrome (24). Participants who were born in severe famine or had Western dietary habits in adulthood had a particularly high risk of metabolic syndrome (24).

Over the past decade, the use of online shopping and home delivery has promoted diets filled with highly processed, energy dense food and increased the risk of sedentary behavior as well. This will further contribute to the burden of hypertension if not addressed well in time.

\section{OPPORTUNITIES}

Modern technologies do provide significant opportunities to prevent and manage hypertension. For example, the widespread use of smartphones and social 
media apps like WeChat make more health-related knowledge and education materials accessible to people regardless of their locations and SES. Another example is that a smart salt jar was developed by a Chinese company to monitor household salt consumption (25). The system not only provided information on household salt usage but also offered health messages and guidance on managing hypertension. Whether it is more efficient than the currently used salt restrictions spoons warrants further research.

The use of modern technologies may also help monitor physical activity, sleep, and the use of hypertension medication. The health and behavior related data collected by different channels provide excellent opportunities for tailored prevention of hypertension as most of them are modifiable risk factors for hypertension.

With the health reform started in 2009, China has delivered a remarkable expansion of health insurance coverage, which provided a better opportunity for treatment of hypertension. The National Basic Public Health Service Project provided hypertension patients aged 35 years old and above with free management service by local primary healthcare workers. The Ministry of Health proposed a "Work plan on NCD prevention and control in China (2012-2015)" and focused on setting up mechanisms of multisectoral cooperation (26). The work plan provided a great opportunity to prevent and manage hypertension by increasing the awareness and control of hypertension, especially among those in rural areas, those with a low socioeconomic status, and those in the young labor force (27).

In conclusion, the control rate of hypertension is steadily increasing in China. However, China still faces a major challenge with hypertension, and it is likely to become worse in the future due to shifts in the population's socioeconomic status and promotion of unhealthier diets and lifestyles. Poor awareness and control of hypertension put tens of millions of lives at risk. Prevention of hypertension should not only target conventional risk factors but also focus on novel risk factors. Priority should be given to the screening and monitoring of hypertension. The use of modern technologies will facilitate prevention efforts and make them more sustainable and effective.

\section{doi: $10.46234 / \mathrm{ccdcw} 2020.210$ \\ \# Corresponding authors: Zumin Shi, zumin@qu.edu.qa; Youfa Wang, youfawang@gmail.com.}

${ }^{1}$ Human Nutrition Department, College of Health Sciences, QU
Health, Qatar University, Qatar; ${ }^{2}$ Global Health Institute, School of Public Health, Xi'an Jiaotong University Health Science Center, Xi'an, Shaanxi, China; ${ }^{3}$ Center for Advancing Population Science, Division of General Internal Medicine, Department of Medicine, Medical College of Wisconsin, Milwaukee, WI, USA.

Submitted: September 06, 2020; Accepted: September 25, 2020

\section{REFERENCES}

1. National Cardiovascular Center. Report on cardiovascular diseases in China, 2014. Beijing: Encyclopedia of China Publishing House. 2015. http://find.nlc.cn/search/showDocDetails?docId=99185423956881940 0\&dataSouce=ucs01\&query $\% \mathrm{E} 4 \% \mathrm{~B} 8 \% \mathrm{AD} \% \mathrm{E} 5 \% 9 \mathrm{~B} \% \mathrm{BD} \% \mathrm{E} 5 \% \mathrm{BF} \%$ 83\%E8\%A1\%80\%E7\%AE\%A1\%E7\%97\%85\%E6\%8A\%A5\%E5\%91 $\% 8 \mathrm{~A} 2014$. (In Chinese)

2. Yang ZJ, Liu J, Ge JP, Chen L, Zhao ZG, Yang WY, et al. Prevalence of cardiovascular disease risk factor in the Chinese population: the 2007-2008 China National Diabetes and Metabolic Disorders Study. Eur Heart J 2012;33(2):213 - 20. http://dx.doi.org/10.1093/eurheartj/ ehr205.

3. Wu YF, Huxley R, Li LM, Anna V, Xie GQ, Yao CH, et al. Prevalence, awareness, treatment, and control of hypertension in China: data from the china national nutrition and health survey 2002. Circulation 2008;118(25):2679 - 86. http://dx.doi.org/10.1161/CIRCULATION AHA.108.788166.

4. Li YC, Yang L, Wang LM, Zhang M, Huang ZJ, Deng Q, et al. Burden of hypertension in China: a nationally representative survey of 174,621 adults. Int J Cardiol 2017;227:516 - 23. http://dx.doi.org/10.1016/ j.ijcard.2016.10.110.

5. Joffres M, Falaschetti E, Gillespie C, Robitaille C, Loustalot F, Poulter $\mathrm{N}$, et al. Hypertension prevalence, awareness, treatment and control in national surveys from England, the USA and Canada, and correlation with stroke and ischaemic heart disease mortality: a cross-sectional study. BMJ Open 2013;3(8):e003423. http://dx.doi.org/10.1136/bmj open-2013-003423.

6. Wang ZW, Chen Z, Zhang LF, Wang X, Hao G, Zhang ZG, et al. Status of hypertension in China: results from the China hypertension survey, 2012-2015. Circulation 2018;137(22):2344 - 56 . http://dx.doi.org/10.1161/CIRCULATIONAHA.117.032380.

7. Shao S, Hua YC, Yang Y, Liu XJ, Fan JG, Zhang A, et al. Salt reduction in China: a state-of-the-art review. Risk Manag Healthc Policy 2017; 10:17 - 28. http://dx.doi.org/10.2147/RMHP.S75918.

8. Hipgrave DB, Chang SY, Li XW, Wu YN. Salt and sodium intake in China. JAMA 2016;315(7):703 - 5. http://dx.doi.org/10.1001/jama. 2015.15816.

9. Tan MQ, He FJ, Wang CQ, MacGregor GA. Twenty-four-hour urinary sodium and potassium excretion in China: a systematic review and meta-analysis. J Am Heart Assoc 2019;8(14):e012923. http://dx.doi.org/10.1161/JAHA.119.012923.

10. Wang YF, Xue H, Sun MX, Zhu XY, Zhao L, Yang YX. Prevention and control of obesity in China. Lancet Glob Health 2019;7(9):E1166 - 7. http://dx.doi.org/10.1016/S2214-109X(19)30276-1.

11. Chen ZM, Smith M, Du HD, Guo Y, Clarke R, Bian Z, et al. Blood pressure in relation to general and central adiposity among 500000 adult Chinese men and women. Int J Epidemiol 2015;44(4):1305 - 19 http://dx.doi.org/10.1093/ije/dyv012.

12. Wang $\mathrm{Y}$, Wang $\mathrm{L}, \mathrm{Qu} \mathrm{W}$. New national data show alarming increase in obesity and noncommunicable chronic diseases in China. Eur J Clin Nutr 2017;71(1):149 - 50. http://dx.doi.org/10.1038/ejcn.2016.171.

13. Chen XL, Wang YF. Tracking of blood pressure from childhood to adulthood: a systematic review and meta-regression analysis. Circulation 2008;117(25):3171 - 80. http://dx.doi.org/10.1161/CIRCULATION AHA.107.730366.

14. Li YP, Jaddoe VW, Qi L, He YN, Lai JQ, Wang JS, et al. Exposure to the Chinese famine in early life and the risk of hypertension in adulthood. J Hypertens 2011;29(6):1085 - 92. http://dx.doi.org/10. 
1097/HJH.0b013e328345d969.

15. Liu LL, Xu XL, Zeng H, Zhang Y, Shi ZM, Zhang F, et al. Increase in the prevalence of hypertension among adults exposed to the Great Chinese Famine during early life. Environ Health Prev Med 2017; 22(1):64. http://dx.doi.org/10.1186/s12199-017-0671-2.

16. Wu L, Feng XQ, He AX, Ding Y, Zhou XW, Xu ZC. Prenatal exposure to the Great Chinese Famine and mid-age hypertension. PLoS One 2017;12(5):e0176413. http://dx.doi.org/10.1371/journal.pone. 0176413.

17. Shi ZM, Nicholls SJ, Taylor AW, Magliano DJ, Appleton S, Zimmet P. Early life exposure to Chinese famine modifies the association between hypertension and cardiovascular disease. J Hypertens 2018;36(1):54 60. http://dx.doi.org/10.1097/HJH.0000000000001496.

18. Zhao LC, Stamler J, Yan LL, Zhou BF, Wu YF, Liu K, et al. Blood pressure differences between northern and southern Chinese: role of dietary factors: the international study on macronutrients and blood pressure. Hypertension 2004;43(6):1332 - 7. http://dx.doi.org/10. 1161/01.HYP.0000128243.06502.bc.

19. Li SM, Bañuelos GS, Wu LH, Shi WM. The changing selenium nutritional status of Chinese residents. Nutrients 2014;6(3):1103 - 14 . http://dx.doi.org/10.3390/nu6031103.

20. Liu LP, Lin G, Wang HJ, Zhang B, Du SF. Selenium exposure and incident hypertension among Chinese adults (P24-020-19). Curr Dev Nutr 2019;3(S1):nzz044.P24-020-19. http://dx.doi.org/10.1093/cdn/ nzz044.P24-020-19.

21. Su L, Jin Y, Unverzagt FW, Liang C, Cheng Y, Hake AM, et al.
Longitudinal association between selenium levels and hypertension in a rural elderly Chinese cohort. J Nutr Health Aging 2016;20(10):983 - 8. http://dx.doi.org/10.1007/s12603-016-0700-7.

22. Li Q, Hsia J, Yang GH. Prevalence of smoking in China in 2010. N Engl J Med 2011;364(25):2469 - 70. http://dx.doi.org/10.1056/NEJ Mc1102459.

23. Li M, Shi ZM. Dietary pattern during 1991-2011 and its association with cardio metabolic risks in Chinese adults: the china health and nutrition survey. Nutrients 2017;9(11):1218. http://dx.doi.org/10. $3390 /$ nu9111218.

24. Li YP, Jaddoe VW, Qi L, He YN, Wang D, Lai JQ, et al. Exposure to the chinese famine in early life and the risk of metabolic syndrome in adulthood. Diabetes Care 2011;34(4):1014 - 8. http://dx.doi.org/10. 2337/dc10-2039.

25. Xian JL, Zeng M, Zhu R, Cai ZJ, Shi ZM, Abdullah AS, et al. Design and implementation of an intelligent monitoring system for household added salt consumption in China based on a real-world study: a randomized controlled trial. Trials 2020;21(1):349. http://dx.doi.org/ 10.1186/s13063-020-04295-1.

26. The Ministry of Health. China national plan for NCD prevention and treatment (2012-2015). http://www.chinacdc.cn/en/ne/201207/t2012 0725_64430.html. (2012-5-8).

27. Guan YQ, Zhang M, Zhang X, Zhao ZP, Huang ZJ, Li C, et al Hypertension prevalence, awareness, treatment, control, and associated factors in the labor force population - China, 0215. China CDC Wkly 2020;2(10):147 - 55. http://dx.doi.org/10.46234/ccdcw2020.040. 